\title{
Replacing Copper with New Carbon Nanomaterials in Electrical Machine Windings
}

\author{
Pyrhönen Juha, Montonen Juho, Lindh Pia, Vauterin Julia, Otto Marcin
}

\begin{abstract}
Electrical machines have significant improvement potential. Nevertheless, the field is characterized by incremental innovations. Admittedly, steady improvement has been achieved, but no breakthrough development. Radical development in the field would require the introduction of new elements, such that may change the whole electrical machine industry system. Recent technological advancements in nanomaterials have opened up new horizons for the macroscopic application of carbon nanotube (CNT) fibres. With values of $100 \mathrm{MS} / \mathrm{m}$ measured on individual CNTs, CNT fibre materials hold promise for conductivities far beyond those of metals. Highly conductive, lightweight and strong CNT yarn is finally within reach; it could replace copper as a potentially better winding material. Although not yet providing low resistivity, the newest CNT yarn offers attractive perspectives for accelerated efficiency improvement of electrical machines. In this article, the potential for using new CNT materials to replace copper in machine windings is introduced. It does so, firstly, by describing the environment for a change that could revolutionize the industry and, secondly, by presenting the breakthrough results of a prototype construction. In the test motor, which is to our knowledge the first in its kind, the presently most electrically conductive carbon nanotube yarn replaces usual copper in the windings.
\end{abstract}

Keywords: Electrical machine, winding material, carbon nanotube yarn, machine design, efficiency improvement, motor prototype construction

\section{Introduction}

Since 2009, with the European Commission Regulation (EC) No 640/2009 [1], continuous incremental improvement in electrical machines has contributed effectively to the low-carbon economy targets set by the European Union, especially in regard to the eco-design requirements for electric motors. Nonetheless, electrical machines are considered a fairly mature technology. This can be observed from the fact that radical innovations, which are usually pioneered in niches, seem to have a hard time to break out. Still, electrical machines hold the potential for significant improvement. Similarly as for other technologies, however, a true breakout innovation for accelerated improvement in electrical machines can only happen by riding along with growth in emerging new technologies and associated markets [2]. Radical advances that would substantially affect the cost, efficiencies and performance of electrical machines call for the introduction of new elements. In particular, new conductive materials are needed to replace the traditionally used metals.

Many of the significant efficiency improvements in electrical machines have been initiated by an emergence of enabling new materials technology. Such emerging technologies have been the development of low loss magnetic circuit steel materials and high energy density permanent magnet materials which provide low-loss excitation for machines [3]-[9]. Nevertheless, considering material physics, traditional materials are reaching their limits; they do not offer clear perspectives for disruptive development of magnetic circuits. Copper and aluminium have been used as conductor materials in rotating machines ever since their introduction by electrical engineering pioneers of the nineteenth century. Substituting copper and aluminium for other metals does not provide a reasonable solution. Silver has only higher conductivity than copper. Moreover, it is an expensive metal. In principle, superconductivity could take the development of machines a giant step further while enabling also considerably higher flux densities than those observed with steel-core machines. Yet so far, no such materials could be developed that remain superconductive in temperatures where rotating electrical machines operate.

\section{Copper ultimately increases losses and resource dependency}

Copper is the most commonly used conductor material in electrical machines. For comparison, the conductivity values for copper and other metals are the following. At room temperature copper has a conductivity of 59.6 $\mathrm{MS} / \mathrm{m}$ and its resistivity temperature coefficient is 3.886 $\cdot 10^{-3} / \mathrm{K}$ [12]. For silver, the respective values are $63 \mathrm{MS} / \mathrm{m}$ and $3.8 \cdot 10^{-3} / \mathrm{K}[11]$. But the improvement 
found by using silver instead of copper would be minor because the density of silver is higher than that of copper, as a result of which the machine mass might even increase. The respective value for aluminium are 35 $\mathrm{MS} / \mathrm{m}$ and $3.9 \cdot 10^{-3} / \mathrm{K}$. Aluminium has thus a lower conductivity, [10] but aluminium is widely used e.g. in the rotors of squirrel cage induction motors [11]. Normal construction steel has a conductivity of about $4 \mathrm{MS} / \mathrm{m}$ and electrical steel qualities can have conductivity values in the range of $1.5-2 \mathrm{MS} / \mathrm{m}[13]$.

Despite the fairly high conductivity of copper, a major share of the machine losses still occur in the copper windings; this phenomenon is denoted as copper losses [13]. A typical industrial motor has a minimum rated point efficiency of $91.4 \%$. At the rated operating point it converts about $1040 \mathrm{~W}$ into heat losses. Of these losses, ca. $45 \%$ are created in the stator winding, $27 \%$ in the rotor windings, $21 \%$ are iron losses and the rest are friction and additional losses [13]. In an induction motor, the copper losses are responsible for ca. $72 \%$ of all the losses in the machine, which corresponds to $750 \mathrm{~W}$ of heat power.

Considering that the demand for valuable metals such as copper is likely to increase tenfold as developing economies surge ahead and that the production of copper requires energy-intensive extraction from its ore, copper is increasingly considered an energy-expensive and carbon-intensive material for use in rotating electrical machinery. Moreover, the levels of cradle-to-gate energy consumption in the production of copper may be very high. Copper has also a relatively high metal density $\left(8960 \mathrm{~kg} / \mathrm{m}^{3}\right)$ which means that copper products may be heavier than comparable other products. Increasing the amount of copper in a machine does hence not necessarily improve the overall energy efficiency of the machine but may negatively affect the carbon footprint of the machine. There also remain the risks associated with growing import dependency on metals. The EU, for instance, is dependent on imports to meet $50 \%$ of its copper demand [14] and, hence, also dependent on globally set high copper prices. Aiming at upgrading the performance and efficiencies of electrical machines, higher-conductivity wires are searched for windings.

\section{Emerging Alternatives from Nanomaterials Research}

Where metals seem to have hit a ceiling, the new nanomaterials may offer a case for more powerful improvement of electrical machines. Theoretical physicists and experimentalists have worked on carbon nanotube (CNT) materials for over two decades, but it has only been recently that the use of carbon nanotubes (CNTs) in concrete applications and construction has become acceptable.
Armchair CNTs are, by structure, highly conductive [15]. Because of the "one-dimensional" and symmetric structure of CNT fibre, the charge carriers can travel along the nanotubes almost without "scattering", which is a phenomenon that is commonly referred to as "ballistic transportation". The almost absence of scattering helps CNTs to carry very high current densities, theoretically in the order of $J=100 \mathrm{MA} / \mathrm{cm}^{2}$ [16]. CNTs could then offer, again in theory, a thousand fold increase in current density compared to that of metals such as copper. Conductivity values in the range of $100 \mathrm{MS} / \mathrm{m}$ have been measured on individual singlewalled armchair CNTs at room temperature, resistivity values in the range of $1.0 \cdot 10^{-8} \Omega \mathrm{m}[11]$, and the resistivity temperature coefficient is negative; $-0.2 \cdot 10^{-3} / \mathrm{K}[17]$. So far, the electrical properties of CNT macrostructures such as yarns and sheets are considerably lower than those of individual CNTs [18]. However, from a theoretical viewpoint and assuming that the intrinsic high conductivity nature holds from the microscopic level of CNTs to the macroscopic level of CNT yarn, it would seem that CNT yarn does, in principle, not have a predefined upper limit for conductivity. This means that the electrical conductivity properties of CNT yarn are still improving day by day as a result of continuous research and development efforts and advances in the field. It is therefore possible to assume that the conductivity of CNT yarn will soon catch up with and even exceed the conductivity of copper, and thereby open up enormous development potential for the electrical machine industry.

Recently, the Japanese-Dutch company Teijin Aramid developed a new spinning technology in collaboration with Rice University in the USA [19]. CNTs are spun to form multi-fibre yarn by wet spinning technology. The industrial applications of the new CNT yarn are, however, still in their infancy. The problem of spinning highly conductive multifibre yarn is with the purity of the CNTs. The Teijin Aramid wet spinning process itself results in high-quality joints between individual CNTs and, as such, has potential to produce high conductivity fibre as soon as the problem of CNT purity is solved rigorously. Though the wet spinning technology is yet at laboratory scale, the techniques provide promising outlooks, and are beginning to bridge the gap between basic research and development for CNT-fibre yarn to meet industrial needs. This assumption is based on observed similarities between development processes of CNT yarn and Twaron Aramid yarns, the latter of which has been successful in scaling up the technology to industrial volumes. Today, it seems that finally it is within reach to improve the conductivity in the electrical machine windings by replacing metals with new CNT fibre materials.

Finally, the most recently achieved resistivity for CNT 
yarn would be low enough to allow for testing yarns in different electrical apparatuses. Applications of carbon conductors have been reported previously, but these experiments predominantly focus on the use of CNT materials in electric devices. Examples of these are the supply of current to an incandescent lamp [19], a $400 \mathrm{~Hz}$ small transformer with CNT windings [20]. Nanostructured carbon materials for electrical applications have also been tested in energy storages $[10,21]$ and in solar cells [12]. The results showed that nanomaterials could have significant potential as electrode materials e.g. as a cathode for wearable and lightweight energy storage devices [22,23,24].

\section{Exploiting CNT Conductivity: An Important Step in the Development of Electrical Machines}

If it will be possible to achieve higher conductivity values by substituting copper for new CNT fibre material in the windings of an electrical machine, most probably the efficiency of the machine will be improved or the dimensions and mass of the machine will be decreased, or both. Such development, consequently, will bring about the need for change in the machine properties determination and design. It will involve fundamental change in the overall design principles of electrical machines.

In present-day electrical machines the operating winding temperature is normally in the range of $120{ }^{\circ} \mathrm{C}$. Under load the copper DC-conductivity decreases to the level of $42.9 \mathrm{MS} / \mathrm{m}$. This is $72 \%$ of the copper conductivity at room temperature. In CNT yarn conductors the resistivity should stay about constant when their temperature has risen to $120^{\circ} \mathrm{C}$. Hence, CNT yarn windings may have multiple operating-temperature conductivity values compared with the conventional copper windings.

A further benefit of CNT yarn conductors is that they consist of very thin sub-conductors which should considerably limit the possibility of skin effect at electrical machine frequencies. The yarn inherently resembles litz wires. Moreover, if we may assume that future commercial CNT yarn will be manufactured from multifibres which can be easily transposed, no circulating circulating currents should appear either. Both skin effect and circulating currents can be very harmful in traditional high-current windings and lead into increased AC-resistance. In the copper conductors of a high-power electrical machine there is always the problem of possible skin effect and circulating currents which make the AC-resistance of copper conductors significantly higher than the DC-resistance value. It is not uncommon that the resistance factor $\left(k_{\mathrm{R}}=R_{\mathrm{AC}} / R_{\mathrm{DC}}\right)$ gets values of
$150 \%$ in higher-frequency applications [11]. In highfrequency, high-temperature applications we might, therefore, theoretically reach a situation where the ACconductance of a carbon conductor is even three-times the conductance of a similar size copper conductor. This should bring about a remarkable change in electrical machine design.

It should then also be possible to design carbonwinding electrical machines that can operate at higher operating temperatures than what we are used to apply in electrical machine design today. This is due to the fact that there will be no increase of Joule losses as the temperature increases. As far as we use steel in the magnetic circuit, its losses get smaller as the temperature increases because the eddy currents will be limited by the increased lamination resistivity. The eddy current losses are inversely proportional to the resistivity of the laminations [9]. The higher operating temperatures will naturally result in new challenges regarding the insulation and permanent magnet materials. Present-day insulation materials seldom can operate in temperatures higher than $220{ }^{\circ} \mathrm{C}$ [11] and NdFeB-based permanent magnets should normally be operated below $150{ }^{\circ} \mathrm{C}$.

Let us assume that in the near future researchers will succeed in manufacturing $100 \mathrm{MS} / \mathrm{m} \mathrm{CNT}$ yarn conductors. Copper conductivity is $59.6 \mathrm{MS} / \mathrm{m}$ at room temperature with a resistivity temperature factor of 3.886 $\cdot 10^{-3} / \mathrm{K}$; at $150{ }^{\circ} \mathrm{C}$ it is only $39.6 \mathrm{MS} / \mathrm{m}$. If eddy currents and circulating currents decrease the practical conductivity further by $20 \%$ we stay at the level of about $32 \mathrm{MS} / \mathrm{m}$ while CNT yarn could maintain its $100 \mathrm{MS} / \mathrm{m}$ at $150{ }^{\circ} \mathrm{C}$. This means that, in practice, we could reduce the Joule losses of a future CNT-yarn electrical machine by two thirds if the machine geometry is kept the same. Already today, the properties of available CNT yarn do allow important niche development, especially in the domain of turbomachinery for instance for special highfrequency high-temperature compressor applications.

Furthermore, CNT fibre materials also allow manufacturing of lightweight and strong electrical conductors. The density $\left(\rho_{\mathrm{CNT}} \approx 1500 \mathrm{~kg} / \mathrm{m}^{3}\right)$ of CNTfibre yarn is about one sixth the density of copper. Already now, the specific conductivity of CNT-fibre yarn $\left(\sigma / \rho\left[\mathrm{Sm}^{2} / \mathrm{kg}\right]\right)$ is close to the level of the specific conductivity of copper. It is therefore realistic to expect that in the near term ongoing efforts to leverage the properties of CNTs will accelerate the development of CNT yarn such that will be able to conduct electricity with the same mass as copper conductors do nowadays. Though the significance of such development will be minor in electrical machines where the space reserved for conductors is limited, nevertheless, it might greatly benefit the development of other, special applications.

And last but not least, the availability of carbonic materials is of major importance for the further 
development of resource-efficient CNT winding machines. Carbon materials are among the most abundant materials on the Earth. As such, the presently high price of carbon-based conductors should decrease with the growth of industrial applications and commercial use. At present, the price of copper is in the range of $10 € / \mathrm{kg}$ and its density is about six times the density of CNT yarn conductor material [25]. It is not expected that CNT yarn conductors will soon beat copper conductors. However, we may expect that in the short term CNT materials will enable the creation and development of new applications and new devices, there where CNT wires can, in niche applications, bring advantage over copper in light weight, flexibility, bending fatigue resistance, resistance to corrosion, high strength and high modulus of elasticity.

Yet today, since the manufacturing development of carbonic conductors is still at laboratory scale, in practice, the conductivity of CNT yarn conductors is still at a modest level; that is $3.4 \mathrm{MS} / \mathrm{m}$, which is in the range of construction steels' conductivities. However, poorer conductive steel can be and is often used in solid-rotor induction motors as rotor conductor material. The presently poorer conductivity of available CNT yarn should therefore not be a barrier for looking at the use of CNT yarn for special electrical machine applications.

With this article, we suggest that is now time to focus research efforts on the largely untapped potential for advance in electrical machine technology offered by already available and future CNT materials as these hold the promise of significantly improving the conductivity in electrical machines. In the following section we present the results of an experiment we have recently conducted. We have designed and constructed the - to our knowledge - first electrical machine in which we have used the presently most electrically conductive CNT yarn to replace the conventional copper wires in the windings. The overall aim of the project was to launch a comprehensive study on the feasibility of improving rotating electrical machine efficiencies and performance by replacing copper with highly conductive new CNT materials. One of the main objectives of the experiment was to demonstrate that there is an urgent need for collaboration between the fields of CNT materials research and engineering research. Collaboration needs to reach a level where scientists and manufacturers will work together so as to increase better understanding of the benefits and challenges regarding the development and application of carbon nanomaterials to improve the energy and resource efficiency of rotating electrical machines.

\section{The Design and Construction of a Small Prototype Machine with CNT Yarn Conductors}

Recently, Teijin Aramid BV, in collaboration with Rice University, has developed CNT yarn with conductivity in the range of $3.4 \mathrm{MS} / \mathrm{m}$. At Lappeenranta University of Technology, we have launched a research project to investigate, understand and demonstrate the feasibility of using CNT yarn, in rotating machine windings. At Teijin Aramid, the CNT fibres are processed in a novel way and the fibres are used to assemble wire gauges, e.g. 26 and 39 AWG CNT based yarn. 39 AWG corresponds to $0.00632 \mathrm{~mm}^{2}$ and has resistance of ca. $50 \mathrm{Ohm} / \mathrm{m}$. The maximum allowable current in this wire is $0.7 \mathrm{~A}$ corresponding to 1100 $\mathrm{A} / \mathrm{mm}^{2}$. In principle, it can operate at several hundreds of degrees Celsius. However, in our motor application a much lower current must be used because the presentday insulation materials should not be exposed to too high operating temperatures. The 26 AWG yarn type was selected for the test motor. This type has a crosssectional surface of $0.1280 \mathrm{~mm}^{2}$, an equivalent single wire diameter of $0.405 \mathrm{~mm}$ and corresponds to CNT yarn of approximately 2000 dtex. Each motor conductor is made of ten parallel 2000 dtex yarns. The motor coil conductors are $1.2 \mathrm{~m}$ long, and their measured resistance is $0.4 \Omega$, yielding only $2.4 \mathrm{MS} / \mathrm{m}$ average conductivity whilst the predicted conductivity was $3.4 \mathrm{MS} / \mathrm{m}$. The yarn has also a small positive temperature coefficient $(0.0008 / \mathrm{K})$ whilst we expected the yarn to have zero or a small negative temperature coefficient. The conductivity level of the sample conductors is thus very low. Therefore, the yarn can be used only for demonstration purposes; that is to show the potential of CNT yarn for application in an electrical machine.

Regarding the test motor manufacturing, we faced the problem that Teijin Aramid CNT-yarn is not provided with insulation. We solved the problem by preparing a tape of parallel conductors (with insulating Twaron yarns as side protection) on insulating aramid (Twaron) paper strip. The turn-to-turn insulation is thus made by using this kind of insulating paper. We recognized that, while having parallel conductors on a flat tape, this might increase the risk of circulating currents in the windings. However, as the winding material has high resistance we decided to ignore this problem for the test machine. Fig. 1 illustrates the conductor material on an Aramid paper tape. For transport purposes the wires are wound on a large paper cylinder. The final conductor is spread on a 9 $\mathrm{mm}$ wide Aramid paper strip so that the surfaces of the flat conductor are insulated just on one side. The crosssectional surface dimensions of the flat conductor with single-sided insulation are $0.5 \times 9 \mathrm{~mm}^{2}$. 


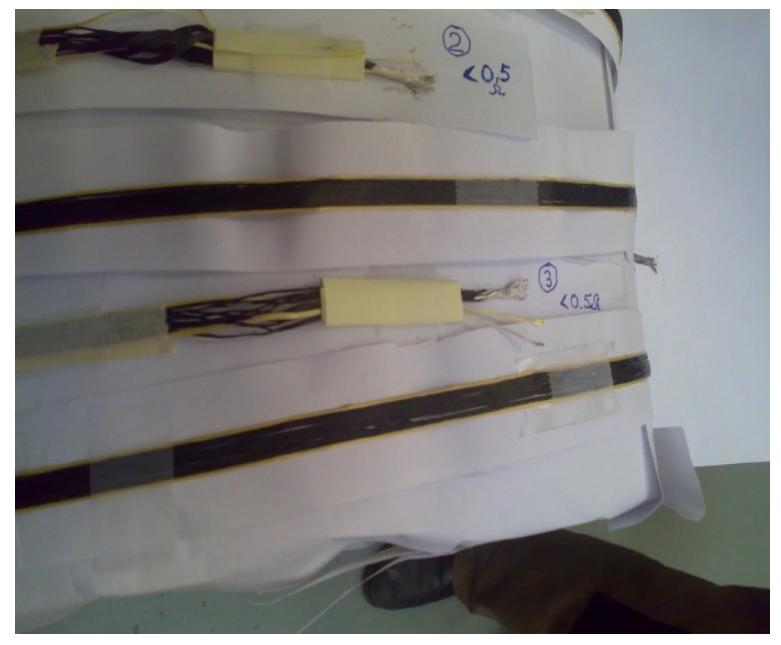

Fig.1. Ten parallel 26 AWG conductors (black ones) with aramid (Twaron) yellow yarns at the edges glued on aramid paper tape strips. In the Fig. the conductors are placed on a white paper cylinder for smooth transporting. The ends of the conductors have been treated by silver solution to allow for sleeve joints to external motor cables.

\section{V.1. The Test Machine}

The high resistance and complicated insulation system of the winding material dictates to a large degree the design of the machine. The winding should have only a few turns and the physical length of the winding must be low enough to minimize the resistive losses in the lowconductivity material. The machine must also be excited by means of permanent magnets to avoid excitation losses in the highly resistive conductors. For this purpose we decided to manufacture a very low voltage permanent magnet $(\mathrm{PM})$ synchronous machine $\left(U_{\mathrm{ph}}=7 \mathrm{~V}\right)$ with $15000 \mathrm{~min}^{-1}$ rotational speed. In high-speed machines, generally, only a very few winding turns are needed. The target was to have less than ten turns per phase winding. To keep the winding work as simple as possible we designed a tooth-coil permanent magnet machine with three stator teeth and two rotor poles which gives $q=0.5$ slots per pole and phase. Table I gives the main design data of the machine.

Table I

CNT-YARN PERMANENT MAGNET SYNCHRONOUS MACHINE DESIGN PARAMETERS IN GENERATING

\begin{tabular}{ll}
\hline \hline Parameter & Value \\
\hline & \\
STATOR MAGNETIC CIRCUIT & \\
Stator stack length $l_{\mathrm{sFe}}[\mathrm{mm}]$ & 42 \\
Stator lamination space factor $k_{\mathrm{Fe}}$ & 0.96 \\
Stator core material & SURA NO10 \\
Stator inner diameter $D_{\mathrm{s}}[\mathrm{mm}]$ & 25 \\
Stator stack outer electromagnetic diameter $D_{\mathrm{se}}[\mathrm{mm}]$ & 75 \\
Number of stator slots $Q_{\mathrm{s}}$ & 3
\end{tabular}

Number of slots per pole and phase $q$

\section{ROTOR}

Rotor outer diameter $D_{\mathrm{r}}[\mathrm{mm}]$

PM cylinder diameter, $D_{\mathrm{PM}}[\mathrm{mm}]$

Rotor PM length, $l_{\mathrm{rPM}}[\mathrm{mm}]$

PM material (N38UH) remanence $B_{\mathrm{r}} @ 120^{\circ} \mathrm{C}[\mathrm{T}]$

PM relative permeability $\mu_{\mathrm{r}}$ at temperature of 120 degrees Celsius

PM material coercive field strength $H_{\mathrm{c}}[\mathrm{kA} / \mathrm{m}]$

Rotor construction: Cylindrical PM is located inside a stainless steel tube with $1.5 \mathrm{~mm}$ wall thickness.

\section{STATOR WINDING}

Winding type

Fractional slot, concentrated, nonoverlapping, single layer $q=$ 0.5

Winding connection: star connected

Number of pole-pairs $p$

Stator coil-turns in series per phase $N_{\mathrm{s}}$

In each coil turn there are 10 strands of $0.4 \mathrm{~mm}$ diameter.

COOLING

Cooling method

Air cooling

A graph of the stator design with softened bending angels at the kinks is shown in Fig. 2, and Fig. 3 illustrates a single stator lamination laser-cut from SURA NO10 and the rotor of the machine.

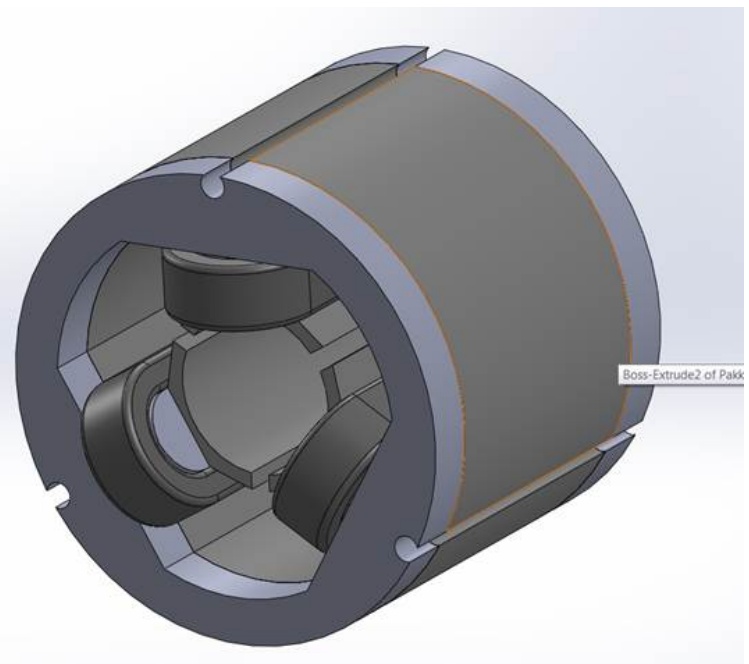


Fig. 2. A graph of the stator design with softened bending angels at the kinks
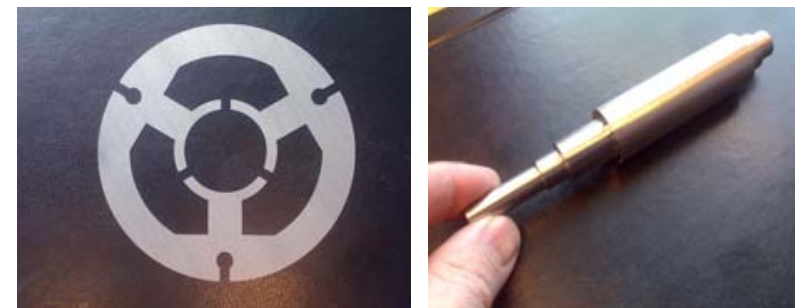

Fig. 3. Single stator lamination sheet on the left and the assembled PM rotor on the right. The magnetic circuit form is designed to reserve rectangular spaces for the cross-sections of the aramid-strip-insulated conductors.

A three-tooth two-pole machine is the simplest possible three-phase machine. It has the benefit that the winding procedure can be simplified when insulated conductors are used, as shown in Fig. 1. The slots are large and therefore the motor could take much more conducting material in the stator. The CNT-yarn space factor is now $15 \%$ and could theoretically be increased to about $50 \%$. This should also significantly lower the carbon losses. However, the insulation system illustrated in Fig. 1, does not allow a better space factor for the conductors. To have a high space factor for the CNT yarn, the yarn should be insulated somehow similarly as enamelled copper wires nowadays are. The rotor of the machine has only one cylindrical NdFeB-magnet in a stainless steel tube which allows to keep the overall design of the machine as simple as possible. In a machine with such high resistance in the winding, PM excitation is, in practice, the only possible option. The rotor is made of four parts, two shaft parts, a stainless steel tube and a cylindrical magnet with $50 \mathrm{~mm}$ length and $20 \mathrm{~mm}$ diameter. The stator stack end finger plates were manufactured to have semi-circular cross-sectional areas which makes the end winding bends as smooth as possible.

\section{V.2. No load and load simulations}

A finite element analysis (FEA) was performed with the CEDRAT Flux 2D software. A dynamic FEA with electric circuit was used to obtain the induced voltages at no-load. The generator load resistances were adjusted to get sufficient output power. Fig. 4 shows the machine air-gap flux density distribution.
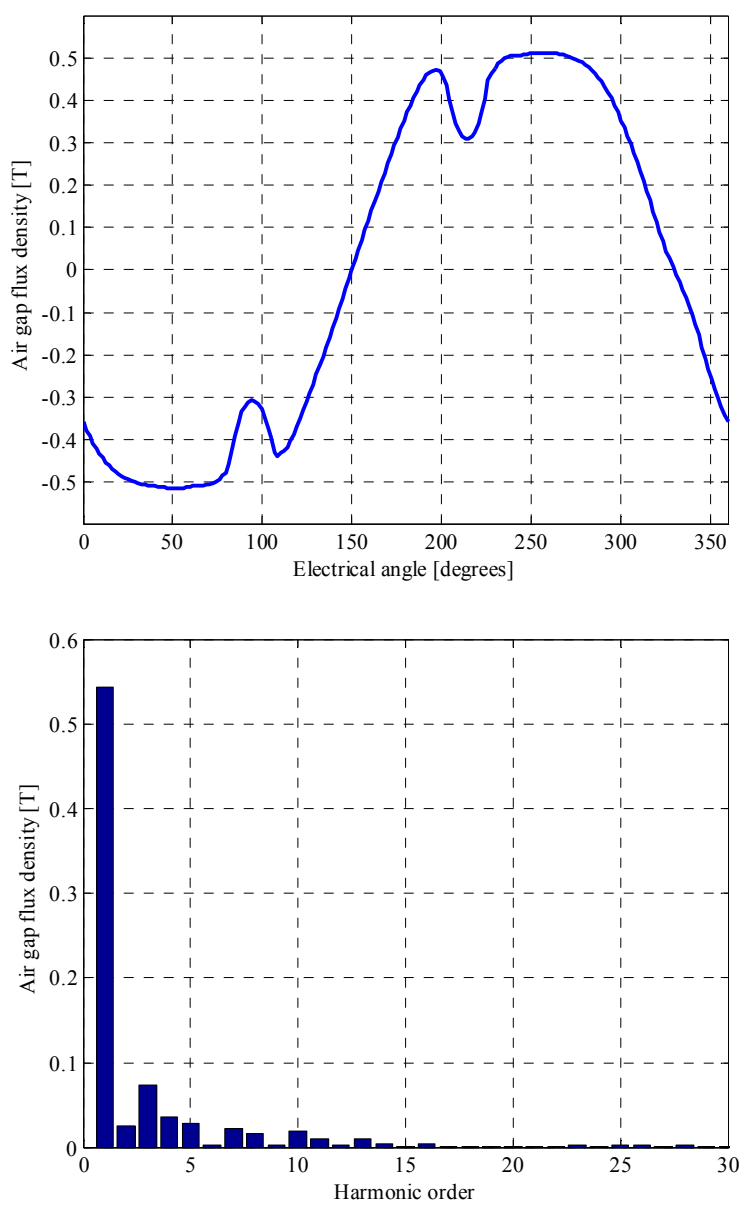

Fig. 4. Air gap flux density peak value $0.51 \mathrm{~T}$ and RMS value $0.361 \mathrm{~T}$. The deep dips in the otherwise fairly sinusoidal waveform result from the permeance variation caused by the slot openings.

Fig. 5 shows the no-load induced voltage and its harmonic spectrum.

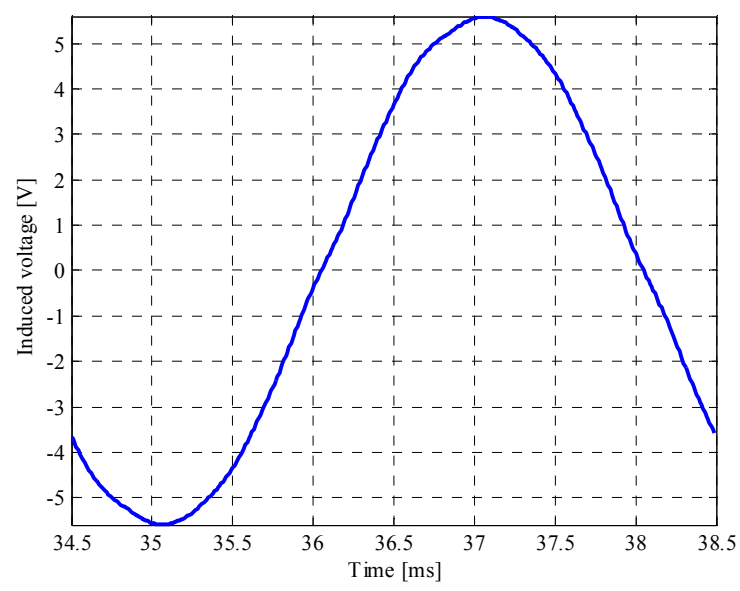




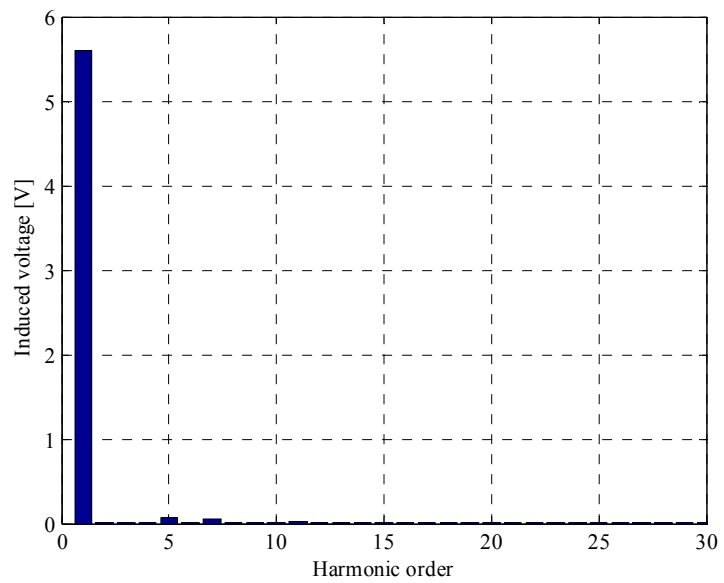

Fig 5. Induced voltage at no-load rated speed $15000 \mathrm{~min}^{-1}$. In addition to the fundamental the voltage contains some fifth and seventh harmonic voltages. The fundamental RMS no-load voltage is $E_{\mathrm{PM}}=$ $3.96 \mathrm{~V}$.

The peak value of the induced voltage per phase is 5.6 $\mathrm{V}$. Induced no-load RMS phase voltage $E_{\mathrm{PM}}=3.96 \mathrm{~V}$. The machine was then simulated as a generator at its rated load. We used generator simulation instead of motoring because the FEA stabilizes much more easily in generating. The phase resistive loads were adjusted to $\mathrm{c}$. $1.33 \Omega$. The voltage and the current curves over one of the load resistors are shown in Fig. 6 and Fig. 7, respectively.

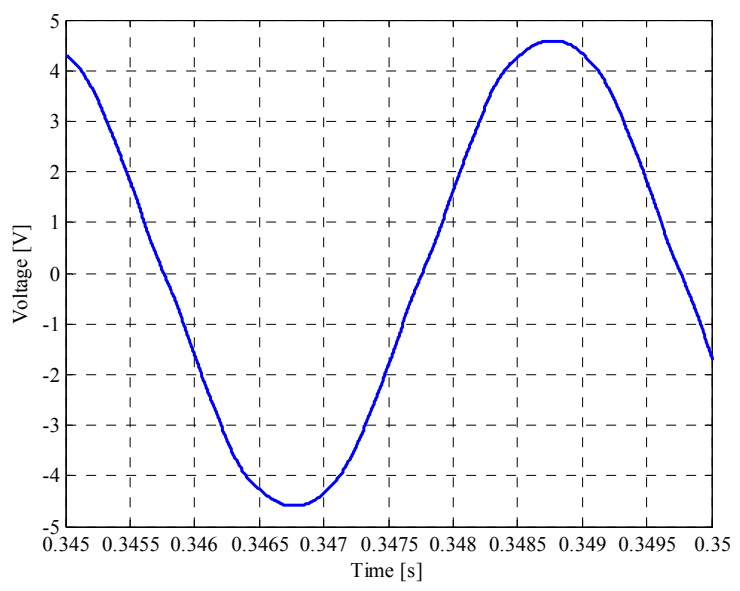

Fig. 6. Phase voltage under generating to $30 \mathrm{~W}$ resistive load.

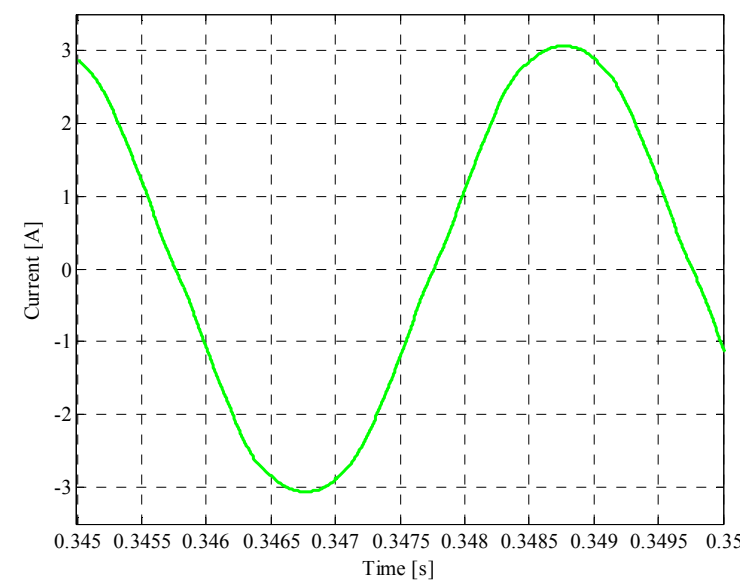

Fig. 7. Phase current under generating to $30 \mathrm{~W}$ resistive load.

The calculated iron losses of the machine at rated operating point are $P_{\mathrm{Fe}}=6.34 \mathrm{~W}$. The Joule losses in the stator - the carbon losses $P_{\mathrm{C}}$ are then $P_{\mathrm{C}}=3 \times 0.4 \times 2.3^{2}$ $=6.35 \mathrm{~W}$. If we would have used copper instead of CNT yarn, the resistance with the same cross-sectional area would have been only $R_{\mathrm{sCu}}=0.022 \Omega$ at $120{ }^{\circ} \mathrm{C}$ operating temperature and the corresponding copper loss $0.35 \mathrm{~W}$. The additional and mechanical losses will be in the range of $P_{\text {Mech }}=1 \mathrm{~W}$. The total loss of the CNT-yarn machine under rated operating is thus about $13.7 \mathrm{~W}$ at generator $30 \mathrm{~W}$ output power. This yields a generating efficiency of about $\eta_{\mathrm{CNT}}=0.69$. With copper conductors the loss would be $7.7 \mathrm{~W}$ and the efficiency at the same operating point in generating $\eta_{\mathrm{Cu}}=0.8$.

\section{V.3. Machine Design Summary and Prototype Manufacturing}

Table II gives the design summary of the machine simulated as a generator.

TABLE II

SUMMARY OF THE MACHINE SIMULATED AS GENERATOR

\begin{tabular}{ll}
\hline \hline Parameter & Absolute value \\
\hline Rated Voltage, V & $3.2 / 5.5$ \\
Rated Current, A & 2.3 \\
Apparent power, VA & 33.8 \\
Rated Input Mechanical Power, W & 43.7 \\
Rated output power, W & 30 \\
Rated speed, rpm & 15000 \\
Rated torque, Nm & 0.019 \\
Back-emf at $15000 \mathrm{rpm}$ & $3.96 / 6.86$ \\
Rated impedance, $\Omega$ & 1.66 \\
Rated inductance, $\mathrm{mH}$ & 1.057
\end{tabular}


Calculated synchronous inductance, $\mathrm{mH}$

The stator laminations were laser-cut and the stack was glued to allow easy manufacturing. The stack was inserted in a steel tube housing and finally the winding material, illustrated in Fig. 1, was used to prepare the windings for the machine. Fig. 8 illustrates the wound stator before and after impregnation. We used normal electrical machine impregnation polyester varnish to mechanically fix the winding and to make sure that no earth faults should take place during the operation of the machine.
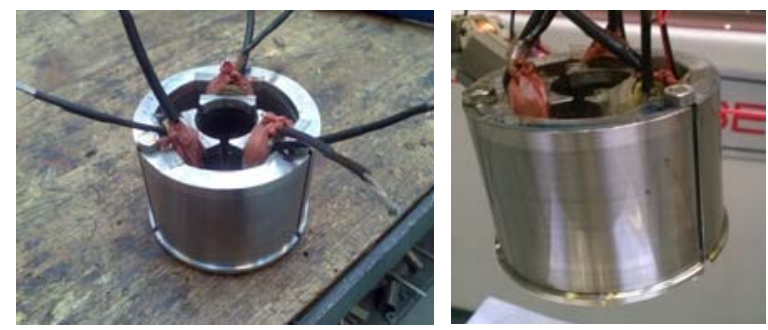

Fig. 8. Machine stator wound with 10 parallel $0.4 \mathrm{~mm} \mathrm{CNTF-wires}$ after the winding manufacturing, left. On the right, the same stator after impregnating. The length of each phase winding is $1.2 \mathrm{~m}$ and the measured DC-resistance is ca. $0.4 \Omega$ at $20{ }^{\circ} \mathrm{C}$. These figures also show the sparse design of the machine to allow easy winding

manufacturing. The CNT yarn space factor is in the range of $15 \%$.

The whole machine was assembled back-to-back with a commercial grinding machine to create a test bench for the generator. The test bench is shown in Fig. 9.

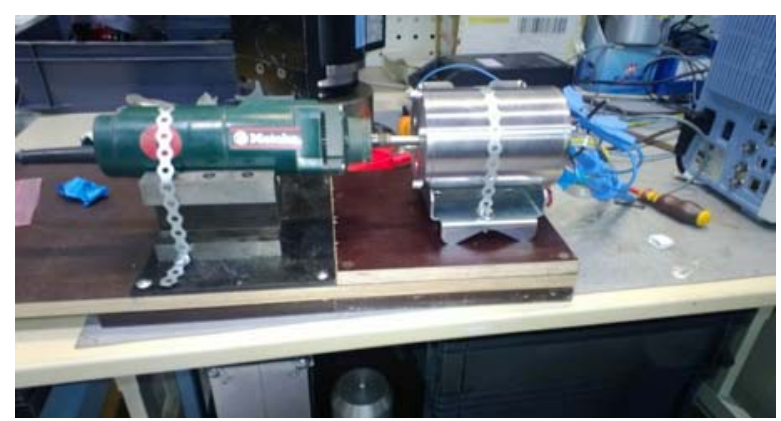

Fig. 9. The machine on the right ready to be tested as a generator. The CNT-yarn-winding machine is on the right and a high-speed commutator motor grinder machine on the left connected back to back.

\section{V.4. Measurements}

We first measured the DC-resistance for the stator assembly. The result of two tests show a higher stator resistance than what could have been expected. Table III summarizes the four-wire DC-resistance measurement results at three different temperatures.
TABLE III

FOUR-WIRE MEASURED PHASE RESISTANCES OF THE TEST MACHINE

\begin{tabular}{llll}
\hline \hline Phase, temperature & $20{ }^{\circ} \mathrm{C}$ & $50{ }^{\circ} \mathrm{C}$ & $90{ }^{\circ} \mathrm{C}$ \\
\hline U, resistance, $\Omega$ & 0.400 & 0.416 & 0.455 \\
V, resistance, $\Omega$ & 0.393 & 0.396 & 0.437 \\
W, resistance, $\Omega$ & 0.388 & 0.390 & 0.430
\end{tabular}

The results indicate that the Teijin Aramidmanufactured CNT wires have a slightly positive temperature coefficient for the resistivity. The slightly positive temperature coefficient may be explained by a slight increase of electron-phonon scattering in the material. The temperature coefficient for the resistivity based on this measurement is in the range of +0.00155 $0.00196 / \mathrm{K}$ which is about $40 \%$ of the corresponding coefficient of copper.

\section{V.4.1. No load Measurement}

The no-load measurement yields promising voltage waveforms as they are purely sinusoidal (Fig. 10) and correspond well to the values calculated with the FEA. The voltage was measured by a Yokogawa power analyser.

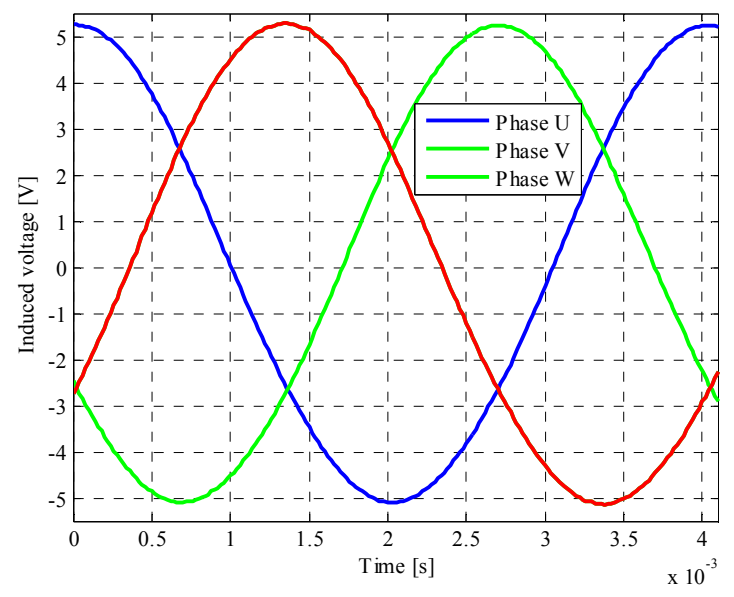

Fig. 10. Induced voltages at no load at $15000 \mathrm{~min}^{-1}$.

Fig. 11 shows that the machine behaves as predicted and the induced voltage increases linearly with the speed until $10000 \mathrm{rpm}$. At higher speed different eddy current phenomena (especially in the rotor magnet retaining stainless steel cylinder) slightly slow down the increasing of the voltage. The curve in Fig. 11 shows that small saturation starts to occur as the speed gets higher. The points indicate the measured values. 


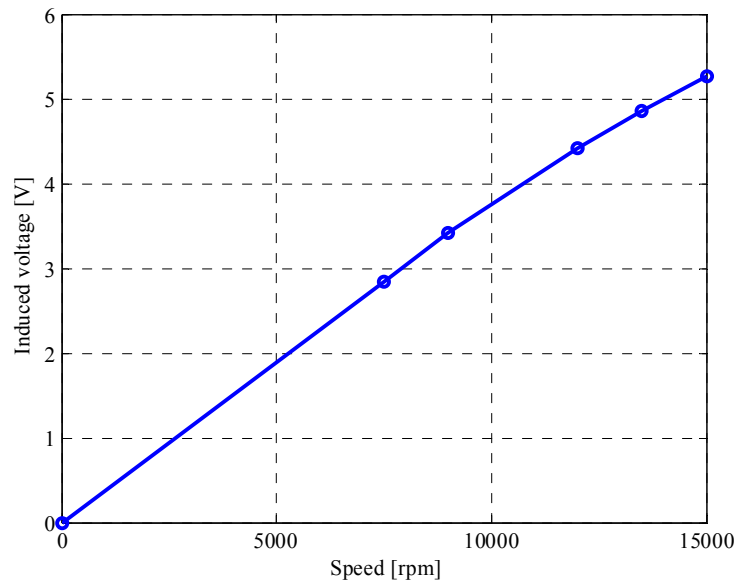

Fig. 11. Induced voltage RMS value as a function of rotational speed.

\section{V.4.2. Load measurement as generator}

In this test, the machine was rotated with external mechanical power supply and the machine was loaded as a generator supplying power to the $1 \Omega$ load resistors which were connected to the machine phase terminals and in star at the other end. Fig. 12 shows the Yokogawa measured voltage and current over one of the load resistors the machine being at room temperature.

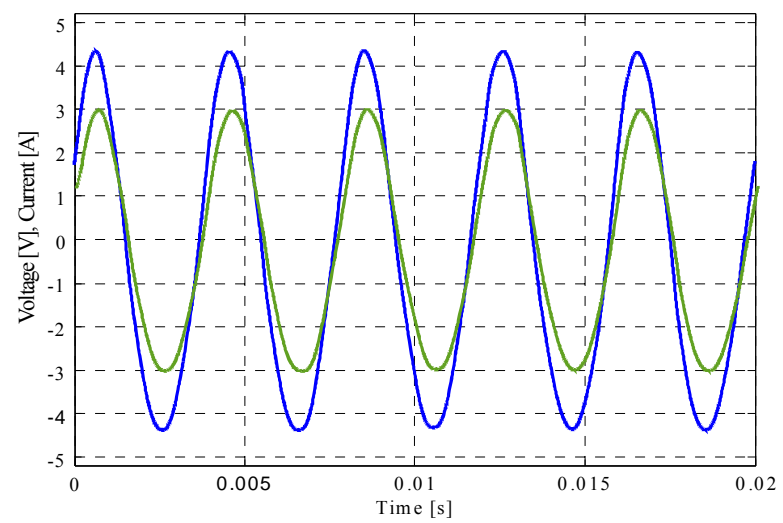

Fig. 12. Measured voltage (peak value c. $4.2 \mathrm{~V}$ ) and current (peak value c. $3 \mathrm{~A}$ ) of the generator operation with resistive load at the speed of $15000 \mathrm{~min}^{-1}$.

\section{V.4.3. No-load measurement as motor}

A small brushless-DC-machine converter, type Trackstar $60 \mathrm{~A}$, was acquired to test the machine also as a motor. The machine was driven in motor mode at noload and the currents and voltages were measured. Fig. 13 presents the no-load voltage at rated speed $15000 \mathrm{~min}^{-}$ ${ }^{1}$ and Fig. 14 the no-load current, respectively.

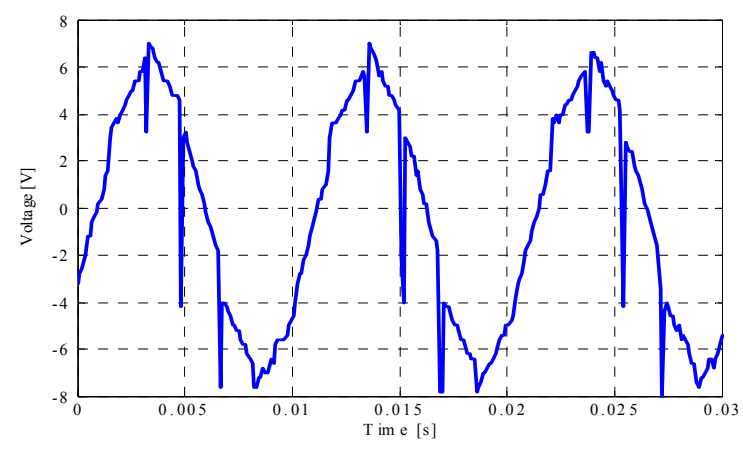

Fig. 13. Voltage of the motor at the speed $15000 \mathrm{~min}^{-1}$ at no-load in converter supply.

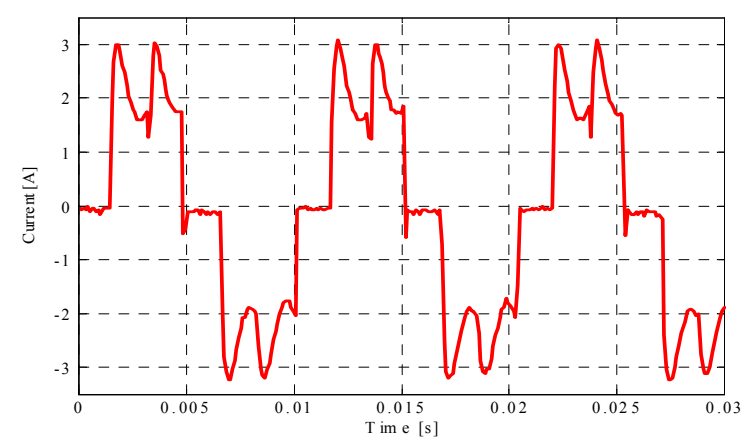

Fig. 14. Current of a motor phase at the speed $15000 \mathrm{~min}^{-1}$ at no-load.

\section{Conclusions}

This article is the first in its kind to introduce a breakthrough approach to the use of new carbon nanomaterials to enable the development of a new generation of rotating electrical machinery. The article scans the environment and indicates some future perspectives for potential applications of carbon nanotube yarn in electrical rotating machines where significant efficiency improvement can be achieved. The topicality of the proposed feature article lies in that is explains the potential for integration of new and greener carbon nanomaterials into electrical machine development and innovation of industrial production lines within the context of the transition towards a more resourceefficient economy. In other words, it shows how it may now be within reach to considerably improve the energy efficiency of those millions of electrical rotating machines that keep industry and society on the move while coupling such development to the important and topical issues of natural resource savings, carbon savings as well as cost savings issues for more sustainable and economic growth.

The articles uses the experimental results from prototype building and testing research the objective of which was to design and measure the world's first electrical motor applying a textile material; windings 
made of carbon nanotube yarn. A prototype of a rotating electrical machine using CNT fibre -based winding material was designed and tested. It demonstrates that CNT yarn has the potential to replace copper in the machine windings. Furthermore, based on the findings from the prototype construction and associated research investigations, the results presented in this article strongly indicate that by replacing copper with advanced conductive CNT materials in the machine windings it may be possible to improve the efficiency and performance properties of the future electrical machine.

Copper has continued to be used as an effective conductor in the electrical machine windings for over a century. However, in the search for higher energy efficiency we must look for a solution that will decrease the losses of electrical machines. Copper losses are the dominating losses in many types of electrical machines and, hence, even a slight improvement in the conductivity of the winding materials may revolutionize electrical machine development and call for redesign of complete production lines in the entire industry.

The experimental results presented here show well enough that further work is needed to pave to way for supreme CNT materials to be integrated into production lines that will change the electrical machine industry. Theoretically, the DC-resistivity of CNT yarn conductors in a future CNT-generation motor is, in practical operating temperatures, significantly lower than that of copper conductors. Very thin sub-conductors also remove all practical skin effect and circulating current related problems which further may increase the benefits achieved from using CNT yarn conductors. A significant reduction in the conductor resistivity should affect the design of machines most significantly. It is then only a question of optimization if we shall exploit the properties of CNT yarn material to design smaller and more lightweight or more energy efficient machines. The CNT-yarn spinning technology is ready for manufacturing of high-conductor materials. As soon as theoretical physicists, materials researchers, engineer researchers and experimentalists will closely together they may succeed in selecting the best of pure metallic CNTs. We believe that then a new era in electrical machine development will start. We may mention that, in the course of writing this article, the best laboratory results measured on Teijin Aramid CNT fibre yarn have been reported to be now in the range of $10 \mathrm{MS} / \mathrm{m}$. Such an increase of conductivity value represents already a significant improvement compared to the CNT yarn material we used in the test motor.

With the introduction of replacing copper with new carbon nanomaterials in electrical machine windings we may have the solution to overcome the challenge of agile development in electrical machines. CNT materials may help realize the vision of building greener, better resource efficient, and better performing electrical machines. Notwithstanding the risk that further technology development in CNT materials will be less fast as may be expected today, the new carbon nanomaterials can be of considerable significance for important niche development in rotating electrical machinery, there where CNT materials have advantage over copper in light weight, flexibility, high bending fatigue resistance, resistance to corrosion, high strength and high modulus of elasticity.

\section{References}

[1] Commission Regulation (EC) No 640/2009 of 22 July 2009. Available at eurlex.europa.eu/LexUriServ/LexUriServ.do?uri=OJ:L:2009:191: 0026:0034:EN:PDF

[2] F.W. Geels, "Technological transitions as evolutionary reconfiguration processes: a multi-level perspective and a casestudy”, Research Policy, vol. 3, 2002, pp. 1257-1274

[3] Z. Wenliang, T.A. Lipo, K. Byung-Il, "Material-Efficient Permanent-Magnet Shape for Torque Pulsation Minimization in SPM Motors for Automotive Applications", IEEE Trans. on Industrial Electronics, vol. 61 n. 10, 2014. pp. 5779-5787.

[4] A.Boglietti, A.El-Refaie, O.Drubel, A.Omekanda, N.Bianchi, "Electrical Machine Topologies: Hottest Topics in the Electrical Machine Research Community", IEEE Trans. on Industrial Electronics magazine, vol. 8 n. 2, 2014. pp. 18-30.

[5] A.Tenconi, S.Vaschetto, A.Vigliani, "Electrical Machines for High-Speed Applications: Design Considerations and Tradeoffs", IEEE Trans. on Industrial Electronics, vol. 61 n. 6, 2014. pp. 3022-3029.

[6] G.-A. Capolino, A. Cavagnino, "New Trends in Electrical Machines Technology - Part I", IEEE Trans. on Industrial Electronics, vol. 61 n. 8, 2014. pp. 4281-4285.

[7] G. -A. Capolino, A. Cavagnino, "New Trends in Electrical Machines Technology - Part II", IEEE Trans. on Industrial Electronics, vol. 61 n. 8, 2014. pp. 4931-4936.

[8] Y. Alexandrova, R. S. Semken, J. Pyrhönen, "Permanent Magnet Synchronous Generator Design Solution for Large Direct-Drive Wind Turbines", 2013, International Review of Electrical Engineering (IREE), 8 (6), pp. 1717-1738.

[9] F. Ismagilov, I. Khayrullin, V. Vavilov,'Electromagnetic Processes in the Rotor Shroud of a High-Speed Magneto-Electric Generator Under Sudden Short-Circuit", (2014) International Review of Electrical Engineering (IREE), 9 (5), pp. 913-918.

[10] J. Liu, R. Younesi, T. Gustafsson, K. Edström, J. Zhu, "Pt/ $\alpha-$ $\mathrm{MnO}_{2}$ nanotube: A highly active electrocatalyst for $\mathrm{Li}-\mathrm{O}_{2}$ battery," Nano Energy, Vol. 10, Nov. 2014 pp. 19-27

[11] K.C.Singh, "Basic Physics", PHI Learning Private Limited, India 2009.

[12] A. F. Mitul, L. Mohammad, S. Venkatesan, N. Adhikari, S. Sigdel, Q. Wang, A. Dubey, D. Khatiwada, and Q. Qiao," Low temperature efficient interconnecting layer for tandem polymer solar cells," Nano Energy, Vol. 11, 2015 pp. 56-63.

[13] J. Pyrhönen, T. Jokinen, V. Hrabovcova, "Design of Rotating Electrical Machines". John Wiley et Sons 2nd edition, Finland 2008.

[14] The European Copper Industry's Manifesto, 2014, available at www.copperalliance.eu/industry/regulatory-framework/voluntaryinitiatives/manifesto (October, 2014) 
[15] X.Wang, N.Behabtu, C.C.Young, D.E.Tsentalovich, M.Pasquali, J.Kono, "High-Ampacity Power Cables of Tightly Packed and Aligned Carbon nanotubes", Adv. Functional Materials 2014.

[16] B.Q. Wei, R.Vajtai, P.M. Ajayan, "Reliability and current carrying capacity of carbon nanotubes", Applied Physics Letter, vol. 79, n. 8, 2001, pp. $1172-1174$.

[17] P.L.McEuen, M.S.Fuhrer,H.Park, "Single-Walled Carbon Nanotube Electronics", IEEE Trans.Nanotech. 2002, 1, pp. 78-85.

[18] M.F.L.De Volder, S.H.Tawfick, R.H. Baughman, A.J. Hart, "Carbon Nanotubes: Present and Future Commercial Applications", Science, Vol. 339, n. 6119, 2013, pp. 535-539

[19] N. Behabtu, C. C. Young, D. E. Tsentalovich, O. Kleinerman, X.Wang, A. W. K. Ma, E.A.Bengio, R. F. ter Waarbeek, J. J. de Jong,R. E. Hoogerwerf, S. B. Fairchild, J. B. Ferguson, B. Maruyama, J. Kono, Y.Talmon, Y. Cohen, M. J. Otto, M. Pasquali, "Strong, light, multi-functional fibres of carbon nanotubes with ultrahigh conductivity", Science 2013, 339, 182.

[20] L. Kurzepa, A. Lekawa-Raus, J. Patmore, K. Koziol, "Replacing Copper Wires with Carbon Nanotube Wires in Electrical Transformers", Adv. Functional Materials, 2014, 24, pp.619-624.

[21] C. Chae, H.-J. Noh, J. K. Lee, B. Scrosati, and Y.-K. Sun, "A High-Energy Li-Ion Battery Using a Silicon-Based Anode and a Nano-Structured Layered Composite Cathode", Adv. Functional materials, 12 Feb 2014, pp 3036-3042.

[22] B. S. Mitchell, "An Introduction to Materials Engineering and Science: For Chemical and Materials Engineers", John Wiley \& Sons, Inc,USA 2004.

[23] S.L. Candelaria, Y. Shao, W. Zhou, X. Li, J. Xiao, J.G. Zhang, Y. Wang, J. Liu, J. Li, G. Zao, "Nanostructured carbon for energy storage and conversion", Nano Energy, Vol. 1, 2012, pp 195-220

[24] R. Rajan Prakash, P. Venkatesh, M. Kottaisamy, S. Arockia Edwin Xavier, "Silicone Rubber MgO Nanocomposite for High Voltage Outdoor Insulation Application", 2013, International Review of Electrical Engineering (IREE), 8 (5), pp. 1642-1646.

[25] H.Shimotani, S.Tsuda, H.Yuan, Y.Yomogida, R.Moriya, "Continuous Band-Filling Control and One-Dimensional Transport inMetallic and Semiconducting Carbon Nanotube Tangled Films", Adv. Functional Materials, 2014.B.Q. Wei, R.Vajtai, P.M. Ajayan, "Reliability and current carrying capacity of carbon nanotubes", Applied Physics Letter, vol. 79, n.8, 2001, pp. $1172-1174$.

\section{Acknowledgements}

The authors wish to acknowledge the support of: Ron ter Waarbeek for spinning the CNT fibres; Peter Akker and Arjan van Haren for assembling the conducting tape; Dr. Hanneke Boerstoel for commenting on this paper, Teijin Ltd. for manufacturing and providing the CNT yarn; Antti Suikki and Jouni Ryhänen for arranging the manufacturing of the test machine mechanics; Harri Loisa for constructing the winding; Manu Niukkanen and Jan-Henri Montonen for arranging the control logic of the converter; Kyösti Tikkanen for arranging the laboratory setup; LUT for funding the prototype design, manufacturing and testing of the prototype machine.

\section{Authors' information}

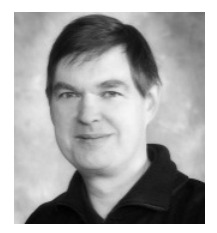

J. Pyrhönen, a Member of IEEE, was born in 1957 in Kuusankoski, Finland, received the Doctor of Science (D.Sc.) degree from Lappeenranta University of Technology (LUT), Finland in 1991. He became an Associate Professor of Electrical Engineering at LUT in 1993 and a Professor of Electrical Machines and Drives in 1997. He is also Head of the LUT Graduate School of Electrical Engineering. He is engaged in research and development of electric motors and electric drives.

His current interests include different synchronous machines and drives, induction motors and drives and solid-rotor high-speed induction machines and drives.

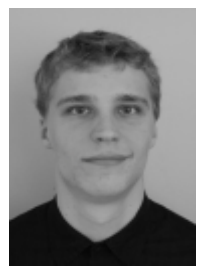

J. Montonen was born in 1988 in Joutseno, Finland, received the Master of Science (M.Sc.) degree from Lappeenranta University of Technology (LUT), Finland in 2012 and Bachelor of Science (B.Sc.) in 2011. He is currently doctoral student in LUT. He is doing the research concerning about electrical machines and drives.

His research work focuses on permanent magnet motors, especially those which are used in different kinds of traction applications.

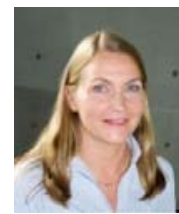

P. Lindh born in Helsinki in 1969, received her M Sc. degree in energy technology in 1998 and her D. Sc. degree in electrical engineering (Technology) in 2004 from Lappeenranta University of Technology (LUT), Lappeenranta, Finland. She is currently serving as an associate professor at the School of Energy Systems, Lappeenranta University of Technology, where she is engaged in teaching and research of electric motors and electric drives.

Her research work focuses on permanent magnet motors, especially concentrated winding machines.

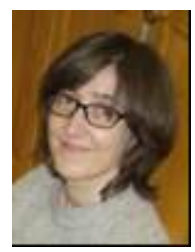

J.J. Vauterin, born in Kortrijk, Belgium, received her Master's degree in philosophy from Gent University (1985), and her Doctor's degree in philosophy from Lappeenranta University of Technology (2012). She is now working as an associate professor at the School of Energy Systems at Lappeenranta University of Technology, where she is engaged in research on issues of knowledge management and societal impact surrounding energy systems development.

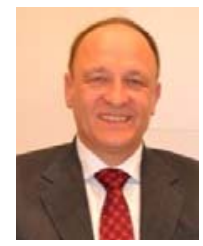

Marcin J. Otto. Business Manager and Project Leader for Carbon Nanotube Fibers at Teijin Aramid BV (The Netherlands). Master of Science in Physics. PhD. Solid State Chemistry (1987).

After starting his career as a scientist, moved quickly to marketing of high performance fibers. $\mathrm{He}$ combines an entrepreneurial and customer oriented approach to business development with scientific knowledge to create a profitable, new supply chain. 